\section{A Sindrome Metabólica e o X da Questão}

$\mathbf{P}$ OR QUE UMA PLETORA de condições mórbidas resolve se juntar num único indivíduo e promover, como objetivo prosaico, sua morte prematura por doença cardiovascular? Respeitada as proporções, esta parece ser uma ampliação do microcosmo intracelular, quando do início do processo de apoptose celular, desencadeando as várias reações que culminam com sua morte. Qual a razão teleológica desses dois processos? O quê determina o início da apoptose celular e da síndrome metabólica, que ao cabo de algum tempo culmina tanto com a morte celular como com eventos cardiovasculares e morte do indivíduo?

Existe alguma analogia entre obesidade, resistência à insulina e hiperinsulinismo e o acúmulo de gordura intracelular e deprivação de glicose? E entre sedentarismo e inatividade celular, e dificuldade de lidar com stress e tensão intracelular?

Era senso comum, há décadas atrás, que alterações patológicas envolvendo o metabolismo de glicídios e lipídios apresentavam-se mais comumente juntas do que isoladas em indivíduos vistos no consultório do endocrinologista. Intolerância aos carboidratos e diabete melito manifesto (apud Fajans e Conn) ocorriam naqueles geneticamente pré-dispostos, bem como hipercolesterolemia e hipertrigliceridemia, isoladas ou combinadas de várias formas, segundo uma antiga classificação de dislipidemias de Friderickson. Freqüentemente esses indivíduos tinham, também, excesso de peso e eram hipertensos. E não raramente tinham ácido úrico elevado com manifestações de "artrite gotosa", tofos dolorosos e inflamados na articulação do hálux, lembrado nas tiras cômicas "Os Sobrinhos do Capitão" pelo próprio Capitão, com sua bengala e a perna enfaixada.

Víamos também que xantomas, xantelasmas, acantose nigricante e esteatose hepática eram manifestações relativamente corriqueiras no exame desses pacientes. Nas mulheres com a então síndrome de Stein-Leventhal, a avaliação do hirsutismo e da infertilidade que antecedia seu preparo para a muito utilizada cirurgia de Taller (ressecção em cunha de tecido ovariano, visando ovulação e gravidez), mostrava a presença habitual de obesidade, quando não hipertensão e diabete. Lembro do Dr. Mário (Mário Ph. Caleiro Lima, professor na Disciplina de Endocrinologia da então Escola Paulista de Medicina) discutindo enfaticamente os casos de síndrome de Achard-Thiers (diabetes da mulher barbada!), além daqueles mais nebulosos que hoje têm elucidados, pelo menos parcialmente, seus mecanismos de doença e nos quais obesidade, hipertensão e dislipidemia eram manifestações freqüentes: síndromes de Lawrence-Moon-Biedl, Seip-Berardinelli, Frölich, Pickwick e muitos outros.

Em nada daquilo se vislumbrava uma solução apropriada naqueles tempos, a não ser as perenes recomendações de regimes rigorosos através de dietas hipocalóricas ( 800 calorias!), estímulo à prática de exercícios físicos e, ocasionalmente, alguma medicação. Na minha época de residente, tínhamos tão somente as anfepramonas, a clorpropamida, alguma coisa ineficiente para o colesterol e um ou outro diurético e só! Comparado à
Claudio E. Kater
Professor Adjunto de Medicina, Disciplina de Endocrinologia, Departamento de Medicina, Universidade Federal de São Paulo, SP. Editor-Chefe, ABE\& M 
crescente gama de medicamentos atuais com diversos mecanismos de ação específicos para tratar cada um desses distúrbios, nosso "arsenal terapêutico" de outrora era apenas um tacape.

Mas havia um co-adjuvante, a fenformina, que foi proscrita por décadas nos EUA por razões até hoje não totalmente esclarecidas (acidose láctica era a justificativa, mas questões estatísticas mal resolvidas do estudo e outros interesses não manifestos liquidaram a medicação). Sua ressurreição, sob a forma de metformina, é mais do que oportuna neste quadro atual, como facilitador da ação da insulina um dos pontoschave do tratamento da síndrome metabólica, como sabemos de sobejo.

A resistência à insulina e a hiperinsulinemia já eram conhecidas, mas apenas no contexto do "diabetes lipoatrófico", quando pacientes jovens resistentes à administração de insulina entravam em ceto-acidose e, ocasionalmente, precisavam de insulina cristalina endovenosa na faixa dos milhares de unidades!

Nos últimos anos, o enorme avanço na compreensão deste conjunto de disfunções metabólicas, hoje conhecido singelamente como "síndrome metabólica", mas inicialmente descrito como "síndrome X" por Reaven, como a expor a plena ignorância de suas causas e porquês, propiciou a realização dessa Edição Especial exclusivamente sobre o tema.

Quero agradecer aos editores convidados, Maria Teresa Zanella, Sandra Roberta Ferreira e Mario Saad, por terem juntado suas habilidades, seus conhecimentos e seus conhecidos e posto em papel uma obra magnífica. Agradeço, também, a todos os autores que foram pontuais e precisos na confecção de seus artigos, permitindo que esta Edição Especial, com material ainda fresco e da mais alta qualidade, chegasse às mãos dos leitores em tempo hábil.

\section{O Volume $\mathbf{5 0}$ dos ABE\&M.}

Neste ano de 2006 estamos publicando o volume de número 50 dos Arquivos. Portanto, é agora que verdadeiramente estamos completando 50 anos de publicação. A divergência de datas acontece por conta dos seis anos de interrupção que a revista sofreu, o primeiro deles em 1956, logo após a morte do seu fundador e editor-chefe, Waldemar Berardinelli, e os outros cinco (1973 a 1977) quando razões variadas minguaram a vitalidade da revista.

Por esse motivo, desde o primeiro número do ano (edição de Fevereiro) introduzimos uma discreta, mas atraente mudança no visual da capa, fazendo-a acompanhar de modificações na composição do Conselho Editorial. Além do Omar Hauache, já informado anteriormente, sentimos informar que nosso prezado Mario Saad também foi obrigado a deixar a Co-editoria da revista por motivos pessoais. Por outro lado, é com grata satisfação que eu anuncio, para substituí-los e para juntarem-se à mim e à Dra. Ana Claudia Latronico na função de co-editores, a Dra. Edna T. Kimura e o Dr. André F. Reis. Sabedores de seu interesse pelas causas da revista, esperamos deles uma participação ativa e dedicada, ao tempo que desejamos a ambos muito sucesso na nova posição.

Ao término de mais um período de gestão da Comissão Editorial Nacional da revista, fizemos também, como de praxe, algumas alterações na composição dos seus membros, permitindo dar sossego e descanso a antigos colaboradores, que vinham prestando serviço à revista desde longa data e muitos deles já aposentados de suas funções acadêmicas e, ao mesmo tempo, estimular e promover outros colegas mais jovens, que têm se destacado no cenário nacional quer por sua produção científica, quer pelo seu interesse e dedicação ao ensino da endocrinologia. A todos eles, novos e antigos colaboradores, agradecemos por tudo o que fizeram, tem feito e ainda farão pelo sucesso dos ABE\&M. 